\title{
LA NEUROBIOLOGÍA ACTUAL EN EL ORIGEN DE LO HUMANO
}

\author{
Natalia López Moratalla \\ Universidad de Navarra
}

\begin{abstract}
Resumen: El proceso evolutivo ha ido de lo simple a lo complejo, a lo largo del tiempo. Y siguiendo la Dinámica de los sistemas irreversibles, alejados del equilibrio. Esta dinámica es epigenética por lo que el proceso avanza hacia una mayor complejidad al aumentar la información. Cada hombre posee además de la información genética y epigenética información relacional. La singular estructura funcional de su cerebro subyace a la capacidad de liberación del encierro en los automatismos de la vida animal siempre en presente.

Palabras clave: neurobiología, origen del hombre.

Current neurobiology in the origin of human.

Abstract: The evolutionary process has gone over time from simple to complex. And following the Dynamics of irreversible systems, far from equilibrium. This dynamic is epigenetic, so the process advances towards greater complexity when the information increase. Each man possesses, in addition to the genetic and epigenetic information, relational information. The unique functional structure of his brain underlies the capacity for release of the enclosure in the automatisms of animal life always in the present.

Keywords: neurobiology, origins of the human.

Recibido: 10 de Julio de 2019. Aprobado: 15 de noviembre de 2019.
\end{abstract}

Como afirma Francisco Rodríguez Valls ${ }^{1}$ al tratar cómo ha surgido una estructura tan compleja como la subjetividad humana, "el ser humano no puede entenderse solo desde un punto de vista especulativo. No hay que construir especulativamente la humanidad sino aceptar lo humano tal y como aparece en su mostrarse empírico".

Como método para descubrir las fuentes de lo humano la interdisciplinariedad exige convocar todas las ciencias que tengan algo que decir. No puede estar ausente la Neurobiología humana. Esta disciplina, emparejada

${ }^{1}$ Rodríguez Valls, F. Orígenes del hombre. La singularidad del ser humano. Ed Biblioteca Nueva, S. L., Madrid, 2017, p. 13. 
con la Nueva Biología aporta hoy día, como ninguna entre las Neurociencias, lo que subyace a la capacidad exclusivamente humana de aflojar las ataduras al dictado de los genes: la libertad. La indeterminación, que procede de ese aflojar las ataduras de lo heredado, la quiebra cada uno con los amores y los hábitos de forma que así se auto-determina.

Ciertamente hay una Antropología desde la corporalidad. Para construirla es imprescindible integrar en ella la dinámica del cerebro humano y apoyarse en la peculiar estructura funcional de un cerebro, que como el de cada hombre no solo lo construye él mismo con su vida, sino que sorprendentemente es ilimitado, aunque quepa físicamente en los estrechos límites del cráneo.

Ciertamente, la enorme especialización de los artículos científicos y su jerga es una seria dificultad en los proyectos interdisciplinares. Pero existen magnificas revisiones y se puede y se debe exigir rigor y estudio para hacer ciencia teórica a los científicos convocados en nombre de la ciencia. Es cierto, que no abundan los científicos teóricos en los equipos interdisciplinares, pero alguien tiene que asumir esa función, o la filosofía no será adecuada para dar respuestas a las grandes cuestiones. Donde hay vitalidad filosófica puede haber capacidad de sacar de un científico naturalista un cultivador de la ciencia teórica.

La ciencia teórica va más allá de la experiencia que es su fuente. Los datos han de integrarse en principios teóricos sin ideologías y sin los intereses espurios de una divulgación que dice a la sociedad lo que la sociedad quiere oír. No bastan los libros divulgativos de grandes científicos. Una importante función de la filosofía - y posiblemente ineludible- es exigir rigor en la respuesta a la pregunta de qué dice la ciencia hoy sobre esta materia $^{2}$. $\mathrm{O}$, tal vez incluso más fácil, que un auténtico filósofo cultive a fondo y con pasión un espacio científico; obviamente no se trata de meterle en un laboratorio — de ese tipo sobran - sino que estudie y sintetice armado de rigor.

${ }^{2}$ López-Moratalla, N. Repensar la ciencia. EUNSA, 2006. 
Tomando la metáfora de la escalera de Wittgenstein debemos tener presente que la Neurobiología actual es Biología Humana y no mera Zoología. De ahí que sea necesario poder dar razón de qué hace que lo vivo tenga un plus de realidad sobre lo inerte, y dar razón del plus de realidad de cada hombre sobre los individuos de cualquier especie.

El hilo conductor es esencial para comprender cada peldaño, porque en el proceso evolutivo hay peldaños de diversa naturaleza en su marcha de lo simple a lo complejo, a lo largo de los tiempos. El gran árbol de la vida tiene el gran peldaño de las raíces que le sumerge en la tierra inerte. Existen peldaños en la formación de las grandes ramas, y al final de la gran rama de los grandes primates ocurre un evento tan singular que da sentido al todo.

Lo que subyace al plus de realidad no de la especie humana sino de cada hombre encontramos respuestas a la singularidad del hombre. Voy a referirme a dos cuestiones: Al hilo conductor de los procesos evolutivos y a las peculiaridades esenciales del cerebro humano.

\section{El hilo conductor de los procesos evolutivos}

El proceso evolutivo ha ido de lo simple a lo complejo a lo largo del tiempo. Se denomina sistema complejo al que está compuesto por varias piezas interactivas, bien ajustadas y reguladas entre sí, que todas contribuyen a la función básica, por lo que la eliminación de cualquiera de los componentes lleva a que el sistema deje de funcionar.

La construcción de un sistema complejo desde uno simple se realiza siguiendo la Dinámica de los sistemas irreversibles, alejados del equilibrio. Requiere que el sistema reciba constantemente materia, energía, o información desde el medio. Solo este permanente cambio les mantiene alejados del equilibrio y autoconstruyéndose en estructuras cada vez más complejas.

Los procesos del mundo inerte dependen de las condiciones del medio. El típico ejemplo es como los átomos de Carbono se constituyen en grafito o en diamante, "según" la presión y la temperatura. 
Por el contrario, y subiendo el enorme peldaño que diferencia el mundo inerte del vivo, todo ser vivo, por simple que sea, tiene un "sí mismo": posee la información genética característica de la especie a que pertenece y se autoconstruye desde esa información propia.

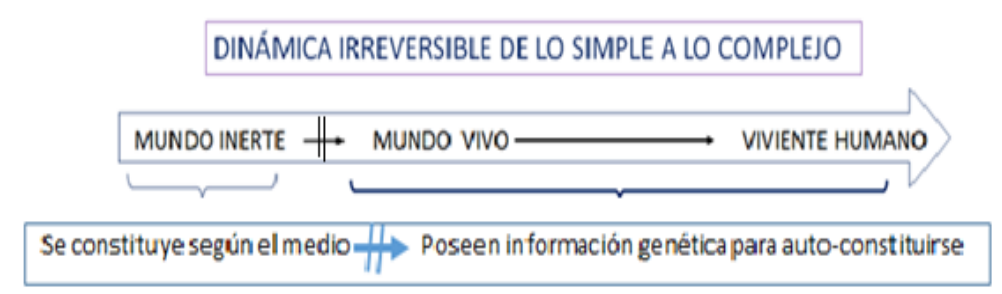

Así, los procesos de cambio evolutivo del mundo inerte se rigen por un mecanicismo causa-efecto: los materiales adquieran una determinada configuración u otra depende además de su naturaleza, de algo externo. Mientras la evolución biológica sigue desde su inicio una dinámica Epigenética tanto para la construcción de los individuos de una especie como para la aparición de nuevas especies ${ }^{3}$.

En cada etapa del proceso la información del material de partida (DNA) se modifica por retroalimentación aumentando así la información genética de inicio. La información de un gen da lugar a un producto (una proteína) que a su vez modifica el DNA de partida. La nueva información que aparece es información epigenética, no está contenida en el material inicial sino que aparece con el proceso. De manera que en cada etapa el resultado es más que la suma de las partes porque la estructura informativa se ha hecho más compleja, a través de modificación química o estructural de la doble hélice del DNA.

Puesto que el material informativo se ha hecho más complejo por la retroalimentación, posee entonces propiedades nuevas que no estaban en la configuración del material inicial. En este sentido se habla de emergencia

\footnotetext{
${ }^{3}$ López-Moratalla, N., G. de Miguel Vázquez, M. Font Arellano, E. Santiago Calvo.La dinámica de la evolución humana. Más con más. EUNSA, 2009.
} 
de propiedades como una consecuencia del cambio de la estructura informativa. Si no se tiene en cuenta la Dinámica Epigenética, la emergencia aparecería como un mero describir algo de lo que se desconoce la causa.

En el genoma de cada especie nos encontramos siempre una serie de genes (secuencias informativas) que se copian a RNA y proteínas. Y otras secuencias no informativas que no se copian a proteínas, sino que sirven de secuencias reguladoras. Es decir, se unen a ellas moléculas (fundamentalmente proteínas) que son señales para que comience a copiarse o a silenciarse un gen localizado cerca de la secuencia. A lo largo de la evolución biológica ha crecido enormemente este DNA no informativo.

El cambio por retroalimentación de su estructura permite el aumento de la complejidad del sistema.

Pues bien, un cambio en el DNA informativo puede hacer que ese gen se malogre o algunas veces se origine una forma de ese gen, que puede hacer, por ejemplo, que los individuos portadores de esa forma tengan unas características en su fenotipo diferentes de las que no lo tienen. Es el mecanismo de adaptación al medio formulado por Darwin: los individuos "mejor" dotados para un entorno en el que se ha producido un cambio, dejan más descendientes. Ese cambio, gradual y en el seno de una población modifica el fenotipo sin cambiar la identidad biológica definida por la información genética y epigenética. La selección natural, externa a los individuos, en momentos de crisis de supervivencia podrá elegir entre los congéneres más aptos — “mejores”- para dejar más descendientes. Es la microevolución darwiniana al servicio de la adaptación al entorno.

Solo en casos extremos, en que una población de una especie quedase geográficamente separada de otra población, y esos hábitats tuviesen condiciones muy diferentes, podría ocurrir que llegara a establecerse una barrera a la reproducción y por tanto a separarse en dos tipos parecidos de la misma especie. Es decir, la acumulación de mutaciones siguiendo el cambio del entorno, podría hacer que la selección natural marcara diferencias en el DNA informativo de una y otra población. Pero estas diferencias no 
son necesariamente de identidad. Difícilmente llegan a separarse dos especies distintas, con su propia identidad genética, sino que basta un pequeño cambio en un carácter fenotípico (por ejemplo, color de las plumas) para que no se dé un reconocimiento reproductor.

Se consideran en Biología los límites de una especie a la capacidad de sus individuos de reproducirse entre sí. Serian subespecies de una misma especie aquellas con caracteres fenotípicos diversos debidos a que la selección natural actúa sobre modificaciones graduales de genes en seguimiento del entorno, o simplemente porque el cambio fenotípico anula un carácter ligado al instinto sexual.

Sin embargo, los cambios en el DNA no informativo suponen un cambio de identidad: una nueva especie. La riqueza del principio vital está en las posibilidades de construcción de un organismo, que de suyo serian ilimitadas. Pero la selección interna (Evo-Devo) filtra. El desarrollo de cualquier organismo es también epigenético: las fases de inicio, desarrollo y maduración se realizan siguiendo su programa de desarrollo. Por tanto, solo habrá avance evolutivo si el cambio en el DNA no informativo da como resultado un tipo de individuo "más complejo" no solo "mejor" en sí mismo. Esto es la Macro-evolución. Después, la selección natural irá mejorando la adaptación al medio de lo aparecido.

El cambio en el DNA no informativo, regulador, modifica el principio vital hacia una mayor complejidad, al actuar sobre el programa de desarrollo de la especie anterior, que de esta forma da paso a la nueva. Lógicamente es un cambio puntual, no en la población; ocurre en la constitución de un nuevo individuo por un evento evolutivo durante la fecundación de los gametos de sus progenitores. También podría darse por cambio en el ADN de uno de los gametos de sus progenitores. En todo caso, la reordenación cromosómica (el terremoto cromosómico) hace que el nuevo individuo sea hibrido (dotación $\mathrm{AA}^{*}$ ) reproducible con sus antecesores (AA). Tras unas pocas generaciones, dado que los híbridos son poco fértiles, se obtendría un genotipo $\mathrm{A} * \mathrm{~A}^{*}$ no reproducible con los anteriores AA. Se ha formado una nueva especie. 
En resumen, los darwinismos mecanicistas quedan superados por la epigenética. La Selección natural como causa queda superada por la Selección Interna según el programa epigenético del desarrollo embrionario. El cambio poblacional y gradual de acumulación de mutaciones por el Equilibrio puntual en unos pocos individuos.

Sin comprender a fondo la riqueza de los mecanismos evolutivos y los grandes peldaños que componen el árbol de la vida, es muy difícil acercarse al singular evento evolutivo que construyo el patrimonio genético humano.

\section{Singularidad del proceso evolutivo humano}

A lo largo del tiempo de la evolución biológica se va produciendo en cada rama del gran árbol de la vida un aumento de complejidad del principio vital causado por la reorganización del material genético no informativo: es un Más con más información genética y epigenética. Más con más es la dinámica de la vida no humana.

Acompaña a este "más" un aumento de la autonomía respecto al medio desde, los microorganismos, a las plantas y a los animales. En el reino animal, a su vez, la autonomía del medio aumenta acompañado en paralelo de la complejidad de su sistema nervioso.

La información de entrada al individuo (un olor, por ejemplo) le dice algo — signo biológico — sobre algo. El olor es signo natural, marca, del alimento adecuado. Pone en marcha las estrategias necesarias y determinadas de la especie para la supervivencia. Solo si tiene hambre, si no el olor no le dice nada. Y sólo se ponen en marcha tales comportamientos en tanto lo huelen, en presente. Es un automatismo específico de la especie, que les capacita para un comportamiento con una cierta autonomía del medio, en lo que se refiere a las estrategias y sociabilidad. 
Natalia López Moratalla

\begin{tabular}{|ll|}
\hline \multicolumn{1}{|c}{ VIDA BIOLOGICA } & \multicolumn{1}{c}{ VIDA HUMANA } \\
\hline Información genética y epigenetica & PLUS de información: RELACIONAL \\
MÁS con MÁS INFORMACIÓN & MÁS con MENOS INFORMACION Genética \\
En función de la especie & Fines propios
\end{tabular}

\begin{tabular}{|c|c|}
\hline בгита מтом' & RTAD) \\
\hline queza biológica: ESPECIALIZACION & Pobreza biológica: In- especialización \\
\hline $\begin{array}{l}\text { Riqueza biológica: mayor principio vital } \\
\text { Automatismos ligados a la edad }\end{array}$ & $\begin{array}{l}\text { Riqueza humana: Principio vital potenciado con libertad } \\
\text { Automatismos ligados a hábitos }\end{array}$ \\
\hline
\end{tabular}

\section{ESTIMULO/RESPUESTA $\longrightarrow$ RESPUESTA SIN ESTÍMULO PRESENTE}

Estimulo más ocasión que causa de la respuesta: Rotura del automatismo: Trabajo. Cultura. signo biológico que dirige el comportamiento Educación. Creatividad. Conducta. Tendencias Presente-Pasado-Futuro. Proyecta su vida. Dependiente de su estado fisiológico Elige. Decide

En el hombre hay un "plus de realidad" debido a que a la información genética y epigenética añade la información relacional propia de cada individuo. El organismo, cuerpo humano, que resulta de la construcción de ese programa es in-especializado, con una pobreza biológica que es presupuesto necesario (aunque no suficiente) para una vida que rompe el encierro en los automatismos biológicos y del estar siempre en presente. De un cierto automatismo respecto al medio de los animales más evolucionados se pasa al hombre con un automatismo respecto a sí, libertad, que le permite a cada hombre liberarse de los encierros del automatismo animal.

Del origen de este plus, que sube un peldaño extra-cósmico, la ciencia solo afirma que no es una propiedad biológica. Pero dice mucho tanto del evento evolutivo que separa a los hombres de los Australopitecinos, tan cercanos al hombre que resulto inviable su organismo. Y especialmente aporta la descripción de la naturaleza de ese peldaño desde el conocimiento de las 
diferencias entre el cerebro de primate y el humano ${ }^{4}$, junto a las características morfológicas del cuerpo humano a que corresponde tal cerebro.

La corporalidad humana no se entiende sin un cerebro humano. No basta fijarse en el tamaño. Hacen falta las leyes que rigen su funcionamiento y su peculiar estructura funcional.

La Paleontología aporta el sitio y el tiempo en que vivió un tipo humano. No puede decir nada acerca de cómo se originó. Al llamar especies distintas de Homo a poblaciones que vivieron en diferentes sitios y diferentes tiempos confunde el concepto biológico de especie. Desde el registro fósil, al igual que de la mera filosofía, no se puede de ninguna manera afirmar si el Homo habilis o el Neandertal era humano o pre-humano, alargando un debate inútil. Una Antropología de la corporalidad no puede hacerse sin la posibilidad de afirmar cuando estamos en presencia de un cuerpo humano.

\section{El peculiar cerebro humano}

El gran peldaño de un automatismo del animal a la libertad humana requiere un cerebro peculiar tanto en su arquitectura como en su funcionamiento ${ }^{5}$.

\section{AUTOMATISMO ANIMAL}

\section{LIBERTAD HUMANA}

$\left.\begin{array}{|l}\text { Contenido genético } \\ \text { Genes reguladores del cerebro } \\ \text { EPIGENÉTICA }\end{array}\right) \begin{gathered}\text { Contenido genético } \\ \text { Genes reguladores del cerebro } \\ \text { Epigenetica + Información relacional }\end{gathered}$

Los eventos evolutivos que dan paso a la aparición del hombre no se deben al contenido genético, al DNA informativo, que incluso disminuye. De hecho, la pobreza biológica — por ejemplo, pierde el gen que participa en el musculo facial necesario para masticar- supone riqueza humana, al

${ }^{4}$ López-Moratalla, N. La dinámica de la evolución humana. Más con menos. EUNSA, 2007.

${ }^{5}$ Cfr. los materiales contenidos en la web: www.lossecretosdelcerebro.com; López-Moratalla, N. El cerebro adolescente. Rialp, 2019. 
hacer posible la sonrisa. Los genes que pierde permiten aflojar la atadura a la biología y poder manifestarse con el cuerpo a sus semejantes.

Sin embargo, aumenta la acción de los genes reguladores del cerebro y con ello aumenta la epigenética en cuanto la construcción del cerebro humano, a diferencia del resto de los órganos. Hay una fuerte epigenética en la construcción del cerebro.

Ahora bien, el gran peldaño es la posesión por parte de cada uno de información relacional. Cada hombre es necesariamente libre y por tanto el plus de realidad es potenciación de su principio vital con libertad. El plus de realidad de cada hombre es la capacidad de liberarse de los encierros en los automatismos biológicos y del presente.

Para ello es imprescindible un plus de realidad del cerebro:

\section{Tres plus en la Arquitectura cerebral}

a) Una enorme región prefrontal que es muy compleja: i) las diversas regiones poseen funciones jerarquizadas según el eje rostro caudal, y ii) contienen circuitos inhibidores, con interneuronas capaces de frenar el flujo de la excitación que procede del sistema límbico. Las interneuronas no completan su migración a esta zona hasta pasados meses después del nacimiento.

b) Los lóbulos parietales poseen una región, los lóbulos parietales superiores, de los que carecen hasta los más evolucionados primates y que sustentan redes neuronales imprescindibles para el trabajo mental.
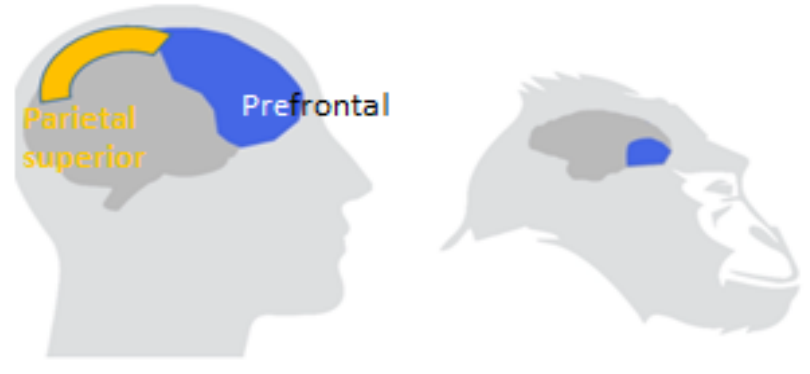
Esta región se desarrolla a lo largo del primer año de vida, a medida que se expande el hueso parietal. Junto a la migración de las interneuronas, muestra, entre otras características que los hombres nacen con el cerebro sin terminar de construirse.

c) Las conexiones entre neuronas forman el gran conectoma, con nodos en que se integran y constituyen redes. A su vez las conexiones se reúnen en fibras, fascículos y láminas cruzándose en rejilla y situándose en direcciones concretas.

Este entrelazamiento hace que la posibilidad de interconexiones funcionales entre las neuronas tienda a infinito y por tanto el espacio físico de cerebro sea ilimitado y soporte de una mente que trasciende espacio y tiempo.

\section{Tres plus en la Arquitectura Funcional}

a) La capacidad de frenar la excitación provocada por el estímulo rompe el automatismo de la respuesta.

b) Una memoria intemporal —a la que subyace la gran red frontoparietal-, que no guarda recuerdos, sino que trae al presente el pasado y simula el futuro, al utilizar regiones cerebrales que se superponen.

El tiempo mental es entonces subjetivo: pasado y futuro no existen en la realidad sino en referencia al sujeto. Permite la subjetividad, la autoconciencia como "yo continuado en el tiempo".
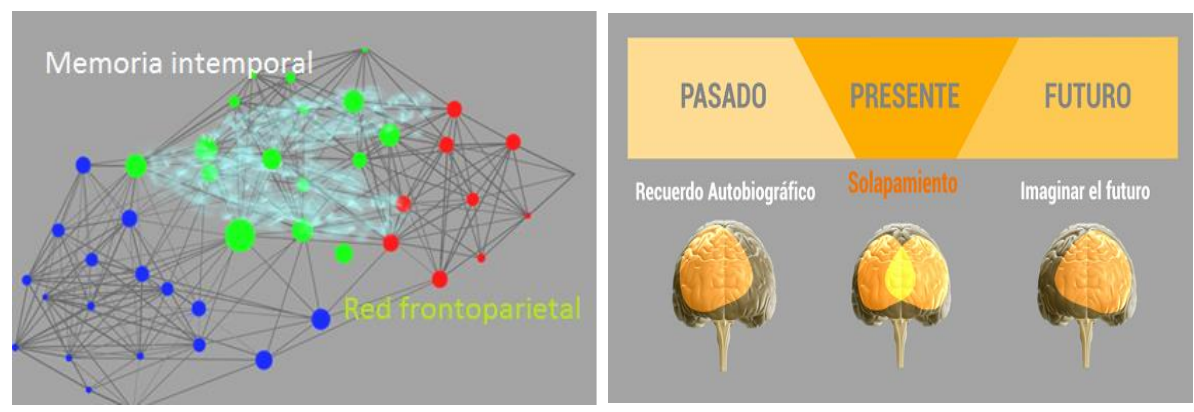
Sin una memoria de este tipo no se entienden las manifestaciones humanas como la tecnica progresiva, la cultura, la estética, etc.

La consciencia animal es solo un "percatarse de"; es en presente. Tal vez, se pueda avanzar algo en la explicación de la autoconsciencia o la interioridad conociendo la red llamada "en reposo" activa cuando no pensamos en nada, ni prestamos atención a una tarea concreta. Curiosamente se funde con la red que simula el futuro.

c) En el cerebro humano lo emocional y lo cognitivo están integrados: i) lo emocional aporta conocimiento de forma que capacita para el juicio moral. ii) la riqueza afectiva humana se debe al contenido cognitivo de las emociones.

\begin{tabular}{|l|l|l|l|l|}
\hline ESTADO & \multicolumn{3}{|c|}{ MALESTAR } & \multicolumn{1}{c|}{ BIENESTAR } \\
\hline Emociones & Miedo & Enfado & Tristera & Alegria \\
\hline Sentimientos & Amenaza/angustia & Disgusto/frustración & Decepción/abatimiento & Buen humor/Satisfacción \\
\hline Afectos & Celos/vergüenza/envidia & Cólera/desprecio & Luto & Amor/Autoestima
\end{tabular}

\section{El plus de una dinámica irregular: caos determinista}

La dinámica de los flujos de información cerebral del cerebro humano supone un peldaño de discontinuidad con los del cerebro animal, precisamente debido a la capacidad de cada uno de frenar el flujo de la excitación.

DINÁMICA CEREBRO ANIMAL $\longrightarrow$ DINÁMICA DEL CEREBRO HUMANO

La dinámica del cerebro animal sigue el lado regular de la naturaleza: la trayectoria es predecible dadas unas condiciones iniciales. También lo son 
algunos procesos del cerebro humano, como los hábitos que se convierten en automatismos queridos que no determinan la respuesta, pero si la facilitan en esa dirección. En ambos casos los flujos de información regulares originan automatismos.

\section{LADO REGULAR DE LA NATURALEZA}

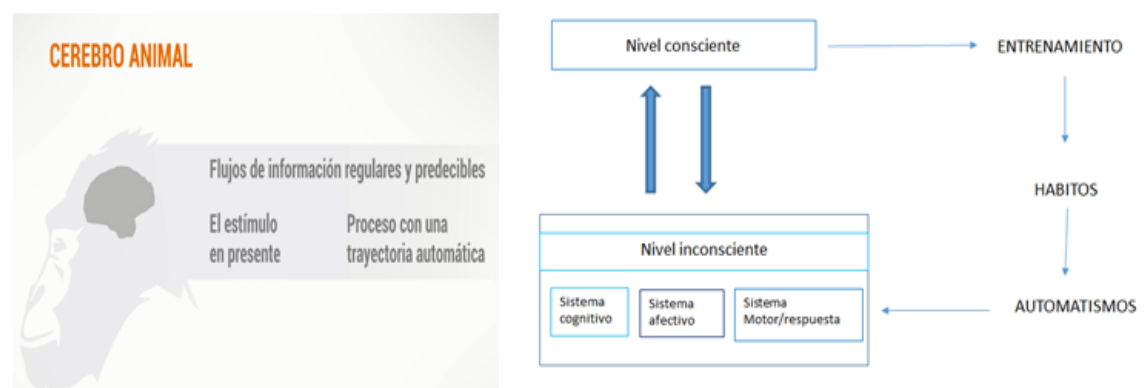

Además, hay sistemas muy dependientes de las condiciones iniciales, de forma que el flujo se hace aperiódico, irregular. En el hombre, el freno voluntario de la excitación de los flujos cerebrales modifica las condiciones iniciales de la trayectoria. Por lo que ésta se indetermina: se rompe el automatismo.

Ahora bien, la dinámica del caos es a su vez determinista en cuanto las trayectorias son atraídas hacia zonas de gran equilibrio dinámico: los atractores. 


\section{LADO IRREGULAR DE LA NATURALEZA}

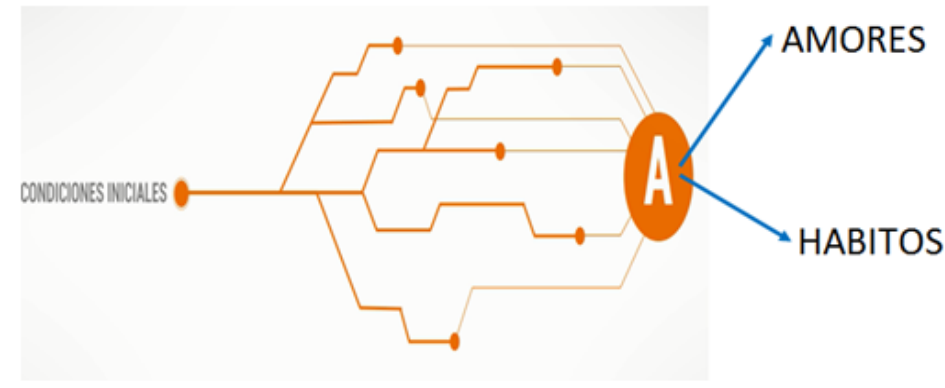

Un gran atractor es la capacidad de amores: el contenido del corazón del cerebro. La afectividad se mide en distancias afectivas (personas lejanas, cercadas o fundidas). La mente guarda como memoria el mapa de la vida afectiva. Constituye un GPS para situarse en el mundo de las relaciones interpersonales. Por tanto, más libertad cuanto más amor.

Más libertad cuantos más hábitos intelectuales y virtudes morales, porque entrenan el cerebro, en una dirección, como también lo hacen los vicios.

Tal atracción a ambos espacios humanos permite que la libertad no sea indeterminación, sino que realmente suponga autodeterminación.

Hoy por hoy conocemos también la elaboración como memoria de varios mapas mentales. El cerebro mide como distancias tanto las geográficas como el tiempo (hace mucho o poco) lo cognitivo (muy abstracto o poco abstracto) y las relaciones interpersonales como distancias afectivas (esta persona me es lejana o cercana). Con las distancias se elaboran los mapas mentales que permiten situarse y orientarse en los mundos correspondientes.

En definitiva, si a la ciencia teórica no le preguntamos por la causa o “donde está la consciencia", sino le preguntamos "qué subyace a", qué es lo necesario, aunque no sea lo suficiente, la ciencia aporta conocimientos que colaboran a la respuesta de la búsqueda de la verdad, el juicio ético, la 
toma de decisiones libres: la naturaleza humana. El programa naturalista se hace ideológico, si va más allá de un método de investigación, y no se convierte en ciencia teórica. La experimentación es necesaria para conocer la realidad, pero no es suficiente.

Natalia López Moratalla natalialm@unav.es 